\title{
FORMAÇÃO DO PROFESSOR DE FILOSOFIA PARA O ENSINO MÉDIO" - UMA ANÁLISE A PARTIR DE DADOS DA REALIDADE FORNECIDOS POR PROFESSORES PARANAENSES
}

\author{
Leoni Maria Padilha Henning ${ }^{1}$
}

Resumo: 0 presente trabalho busca analisar a formação do professor de Filosofia para o ensino médio a partir de dados obtidos em respostas a questionário oferecido a um conjunto de professores especialmente atuantes em Londrina e região (NRL), incluindo alguns pertencentes a outro Núcleo Regional vizinho. O texto é constituído por duas partes nucleares, sendo a primeira delas pautada em dados fornecidos pelo Censo 2011 do estado do Paraná, nos quais podemos situar os professores de Filosofia no estado, no município de Londrina e região. A segunda parte apresenta as respostas fornecidas pelos professores de Filosofia a partir das perguntas constituintes de questionário elaborado para este fim. O conjunto desses dados é analisado neste estudo, tendo alguns autores balizas teóricas importantes nas observações, sugestões e encaminhamentos finais do texto. Acreditamos que, diante da histórica situação de entrada-esaída no institucionalizado âmbito escolar brasileiro, a disciplina requer atualmente profissionais atentos aos argumentos sobre os quais sustentam o seu trabalho. Se a Filosofia está presente no atual currículo escolar, é preciso que se tenha claro qual é a sua proposta no rol das demais disciplinas, os problemas que enfrenta e os possíveis caminhos a seguir. O "ensino de Filosofia" passa a ser então um problema imperativo aos filósofos, especialmente aos filósofos da educação.

Palavras-chave: Ensino de Filosofia. Ensino Médio. Formação de professores.

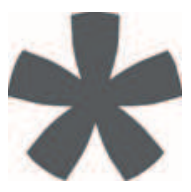

1 Doutora em Educação (UNESP) e Pós-Doutorado (Pós-Graduação em Filosofia, UFSC. Atualmente desenvolvendo atividades de pesquisa e docência na graduação e pósgraduação no Departamento de Educação da Universidade Estadual de Londrina. Email: lhenning@uel.br 


\section{"PHILOSOPHY TEACHER TRAINING FOR HIGH SCHOOL" - AN ANALYSIS FROM DATA OF REALITY SUPPLIED BY TEACHERS FROM PARANÁ}

Abstract: This paper analyzes the formation of the Philosophy teacher for high school from data obtained in response to a questionnaire given to a group of teachers who work especially in Londrina and region (NRL), including some belonging to a neighbor Regional Education Center. The text consists of two core parts, the first of which ruled on data provided by the Census 2011 of the state of Paraná, in which we can situate the philosophy teachers in the state, in Londrina and region. The second part presents the answers provided by philosophy professors from the questionnaire questions prepared for this purpose. All these data is analyzed in this study, having some of the authors important theoretical beacons in the comments, suggestions and final referrals of the text. We believe that, given the historic and input-output situation in the institutionalized Brazilian school environment, such a course currently requires professionals aware of the arguments on which they sustain their work. If Philosophy is present in the current school curriculum, it needs to be clear its proposal in the list of other disciplines, the problems it faces and possible ways forward. "Philosophy Teaching" then becomes an imperative issue to philosophers, especially the philosophers of education.

Keywords: Philosophy Education. High school. Teacher training.

\section{“FORMACIÓN DE PROFESORES DE FILOSOFÍA PARA LA ENSEÑANZA SECUNDARIA" - UN ANÁLISIS DE LOS DATOS DE LA REALIDAD, PROPORCIONADA POR MAESTROS DE PARANÁ}

Resumen: Este artículo analiza la formación del profesor de Filosofía de la escuela secundaria, a partir de datos obtenidos en respuesta a un cuestionario dado a un conjunto de maestros que trabajan en Londrina y región (NRL), entre ellos algunos pertenecientes a otro Centro Regional vecino. El texto consta de dos partes principales, la primera de las cuales fue orientada por los datos proporcionados por el Censo 2011 del estado de Paraná, en el que podemos situar a los profesores de filosofía del estado, de Londrina y región. La segunda parte presenta las respuestas, proporcionadas por los profesores de filosofía, a las preguntas del cuestionario elaborado para este propósito. Todos estos datos son analizados en este estudio, con algunos autores de importantes balizas teóricas en los comentarios, sugerencias y referencias del texto final. Cremos que, dada la situación histórica y de entrada-e-salida no institucionalizada en el ámbito escolar brasileño, la disciplina actualmente requiere de profesionales conscientes de los argumentos en los que sustentan su trabajo. Si la filosofía está presente en el currículo escolar actual, es necesario tener clara su propuesta dentro de la lista de otras disciplinas, los problemas que enfrenta y las posibles formas de avanzar. "La enseñanza de la Filosofía", entonces se convierte en un asunto imperativo para los filósofos, especialmente los filósofos de la educación.

Palabras clave: Enseñanza de filosofía. Enseñanza media. Formación de profesores. 


\section{Introdução}

“Garantir a qualidade no ensino de Filosofia” - eis uma preocupação dos profissionais envolvidos com o ensino de filosofia desde 2008, quando foi firmada a decisão do retorno obrigatório da disciplina às salas de aula do ensino médio no Brasil. Efetiva-se, naquela data, um coroamento vitorioso desencadeado por um longo processo de muitas lutas movidas pelo desejo de ver a disciplina retornar ao currículo como presença obrigatória e que, igualmente, foram nutridas pela certeza de que um adequado tratamento dos conteúdos filosóficos faria uma diferença, senão decisiva, pelo menos significativa, na formação dos jovens. No entanto, desde então, tal diferença haveria de ser sustentada no dia a dia do trabalho desses profissionais. Descortina-se, assim, uma problemática que envolve não somente esses professores, mas os filósofos e educadores em geral, filósofos da educação, administradores e legisladores escolares, os pais e mesmo os alunos e, particularmente, aqueles responsáveis pela formação dos professores da disciplina, agora comprometidos com expectativas que se multiplicam para além dos espaços acadêmicos. Essas razões solidificam iniciativas de grande importância, como a realização de eventos anuais e sistemáticas publicações de artigos, livros, teses e dissertações em que observamos o pulsar de preocupações manifestas tanto por filósofos como por educadores, uma vez que a incursão ${ }^{2}$ de uma nova disciplina nas escolas não somente provoca inquietação pelos profissionais diretamente responsáveis pela realização desse trabalho, mas também exige um acompanhamento contínuo daqueles envolvidos com o funcionamento saudável das instituições educativas. Contudo, vimos observando que a preocupação do retorno da Filosofia ao ensino médio - como também, o adentramento ${ }^{3}$ dessa disciplina nos âmbitos de escolaridade infantil e fundamental - tem ampliado tal preocupação para outros segmentos, como as famílias, os pais em particular e líderes políticos, dos quais temos observado a manifestação de argumentos nem sempre claros e aceitáveis, mesmo porque sem a explicitação de razões claras e

\footnotetext{
2 “Incursão", neste sentido, revela a introdução súbita da disciplina no currículo escolar, configurando-se como quase uma invasão ou ataque!

${ }^{3} \mathrm{O}$ uso da palavra adentramento, do mesmo modo, manifesta o forte sentido de uma espécie de penetração - quase indevida - da disciplina na educação infantil e no ensino fundamental, particularmente.
} 
convincentes e, em alguns casos, impregnadas por preconceitos e julgamentos equivocados.

Assim, considerando o "grande acontecimento" ocasionado pela data acima aludida, percebeu-se, depois de alguns anos, que com ela apenas se conquistara um marco, a partir do qual as ações haveriam de ser desencadeadas com muito cuidado e atenção especiais e contínuos. Estamos, pois, desde aquela data, diante de outro problema, inevitável e imperioso, que deve ser enfrentado diuturnamente em vista de garantirmos a continuidade da presença da Filosofia nos currículos do ensino médio. Com efeito, os esforços dos seus profissionais precisam mostrar uma qualidade inquestionável do ensino que realizam, tornando-o, portanto, combativo frente às ameaças que sempre aterrorizaram a disciplina na escola, as quais orbitam, particularmente, em torno da relevância ou não do seu conteúdo para a formação do jovem.

Com efeito, após os anos que se sucederam desde a sua obrigatoriedade, pontuados de ensaios e erros, de tentativas bem sucedidas, de ações compensatórias e de correções necessárias realizadas nesse processo, de quando em vez, as ameaças ressurgem, muitas vezes de forma velada, quando observamos, por exemplo, outras opções disciplinares sendo apresentadas, segundo uma visão mais competitiva para o atual momento. Há, contudo, aquelas suspeitas em relação à disciplina simplesmente geradas por uma espécie de insegurança própria de uma situação ainda em adaptação à boa novidade da reintrodução da Filosofia nas escolas da forma inédita, como fora ditada pela Lei $n^{\circ} 11684 / 08$. Ainda, encontramos argumentos proferidos até mesmo por personalidades influentes que se dizem preocupadas com o alto volume de informações oferecido aos adolescentes por um currículo exageradamente enciclopédico, o que, segundo este ponto de vista, poderia até gerar a desmotivação e dissipar os seus interesses.

Nesse ponto da apresentação do problema central que este texto propõe analisar, chegamos a, pelo menos, duas importantes dimensões a serem consideradas: 1) Quais as questões, então, que rondam o efetivo trabalho dos professores de Filosofia junto aos adolescentes do ensino médio e como esses profissionais se sentem e se comportam diante desses problemas? 2) Que tipo 
de trabalho é realizado nas universidades para a formação desses profissionais, preparando-os adequadamente para o enfrentamento dessa atuação? Tais aspectos, a meu ver, não deveriam ser, por princípio, pensados como sendo próprios a diferentes conjuntos de problemas ou dimensões relacionadas a naturezas opostas e distantes uma da outra. Ao contrário, defendo que são dimensões que devem ser vistas articuladas, no sentido de juntas constituírem "o problema do ensino de Filosofia", a saber, um conjunto de elementos próprios das condições reais das quais pululam os desafios a serem enfrentados pelos professores, considerando ainda os aspectos inerentes à formação que eles tiveram nos cursos de Licenciatura, tornandoos capazes (ou não) de encaminhar soluções frente a esses desafios. Esperase, contudo, que com boas iniciativas tomadas por esses cursos, evitar-se-ia o abandono da profissão, fomentar-se-ia o desprezo pelo pessimismo crescente que parece estar sendo cultivado em alguns grupos de professores e que pode articular-se ao imobilismo ou, ainda, mostrar-se-ia que somente o uso de artifícios "didáticos", muitas vezes, pode denotar o esquivar-se das responsabilidades profissionais com "engendrados ensaios" que nada têm de filosófico.

Assim, com base nas questões sugeridas pela realidade objetiva que se nos mostra e aquelas anunciadas acima sobre o "problema do ensino da referida disciplina", do modo como o entendemos, tomamos para investigação, como ponto de partida deste estudo, a situação particular dos colégios pertencentes principalmente ao Núcleo de Londrina-PR, o segundo maior do estado dentre um conjunto de 32 NR (Núcleos Regionais). A título de ampliar o número de participantes do estudo, incluímos outros professores próximos à região dispostos a contribuir, sendo alguns deles vinculados também à rede particular ou a outros municípios, como Apucarana, cidade vizinha à Londrina, por exemplo. Tendo definido os professores que trabalham com a disciplina de Filosofia no ensino médio circunscritos à região referida, elaboramos e enviamos um questionário com a finalidade de colher os dados da realidade relacionados com a problemática acima anunciada, a partir de cuja coleta procedemos à análise incorporando as contribuições desses profissionais para o desenvolvimento do estudo. 


\section{Desenvolvimento}

I. Iniciamos o estudo nos pautando no Censo de 2011, a partir do panorama geral da docência no ensino médio do estado do Paraná em relação aos docentes formados nos cursos de Licenciatura e Bacharelado em Filosofia, em cujo território podemos melhor entender alguns elementos presentes na situação da região de Londrina, constituída por 19 municípios, e que se localiza na parte norte do estado. Nesse amplo universo, consideramos primeiramente, os docentes formados nos mais diversos cursos no Município de Londrina e região (NRL) e que totalizam 3.115 Licenciados, indicando comparativamente a existência de um outro grupo de apenas 105 docentes formados em Filosofia - Licenciatura. E, em relação aos Bacharéis que atuam na região do NRL em um número de 634 docentes, encontramos somente um grupo de 03 profissionais formados em Filosofia - Bacharelado. Observamos, claramente, uma desproporção considerável dos números de docentes formados em Filosofia em comparação com os demais profissionais com formação realizada nos mais diversos cursos de Licenciatura e Bacharelado. Isso nos sugere que ocorre uma necessidade de aqueles profissionais ministrarem a disciplina de Filosofia no ensino médio, a qual nos parece estar sendo oferecida grandemente por professores formados em outros cursos. Assim, dentre os professores de Filosofia (com licenciatura e bacharelado no curso de Filosofia) em todo o estado do Paraná (âmbitos estadual, federal, municipal e particular) cujo número totaliza 1.521 profissionais (1.423 licenciados; 98 bacharéis), temos apenas 67 deles (65 licenciados; 02 bacharéis) que atuam apenas no município de Londrina, totalizando em toda a região deste município (NRL) o número de 108 docentes (105 licenciados; 03 bacharéis). Assim, do total de 108 docentes, estão em Londrina 67, e o restante dos 41 docentes (40 licenciados; 01 bacharel) se encontram nos demais municípios da região.

Há que se considerar que esses números não nos permitem a precisão desejada, uma vez que um mesmo professor pode estar localizado em diferentes colégios e mesmo em diferentes municípios da mesma região e, assim, pode estar sendo contado mais de uma vez nos números suprarreferidos. Considerando esses números dos profissionais que trabalham 
com a disciplina de Filosofia no ensino médio - mesmo que tenhamos observado que se trata de números aproximados - mais o total dos 97 estabelecimentos de ensino (apenas estaduais) em funcionamento nos 19 municípios, a nosso ver, estamos diante de um universo desproporcionalmente amplo, para a absorção de um número tão reduzido desses profissionais.

Considerando nesse universo profissional do NRL, o total dos 108 docentes (105 licenciados e 03 bacharéis, nos 04 âmbitos de atuação), observamos uma maior fatia de absorção desses professores na rede estadual de ensino (69 docentes), seguida da rede particular (31 docentes), com decréscimo significativo na rede municipal (07 docentes) e federal (01 docente). Desse modo, ao analisarmos apenas o município de Londrina e encontrando 67 dos professores atuando nos 04 âmbitos de trabalho, dos quais, como apontamos, 65 são licenciados e 02 bacharéis (01 na rede federal; 01 na rede particular), destacamos os 44 professores - todos licenciados - que estão empregados na rede estadual de ensino. Com os dados apresentados, notamos a empregabilidade dos graduados em Filosofia em Londrina concentrada nos cursos de Licenciatura, estando apenas 02 professores bacharéis localizados no universo dos 67 docentes. Como vimos, a mesma desproporção, apontada anteriormente quanto ao número de professores formados no curso de Filosofia e a demanda escolar, se dá ao considerarmos todo o NRL com os seus 19 municípios e com um total de 98 Colégios Estaduais, sendo 57 deles localizados apenas em Londrina.

Interessante observarmos o retrato numérico representativo no que diz respeito à rede municipal em todo o estado do Paraná, que emprega 173 profissionais licenciados e 20 bacharéis em Filosofia, contra apenas 07 licenciados no curso em Londrina e região, não constando nenhum bacharel.

Com os dados revelados, entendemos que ainda encontramos uma carência de professores formados em Filosofia para o provimento da docência na disciplina no ensino médio, tanto em nível de estado quanto em nível do NRL, não obstante havendo o registro de concursos públicos para esse suprimento realizados nos anos 2004 e 2007, este último após o Parecer de 2006 (CNE/CEB no 38/2006), que imputou à disciplina o status da obrigatoriedade. 
II. Numa segunda etapa do estudo, elaboramos e distribuímos um questionário dirigido aos professores para apreender as condições recentes da docência na disciplina, conforme os dados anteriormente coletados em relação ao Núcleo Regional de Londrina (NRL) - Paraná. Este estudo originalmente foi planejado com o interesse de elaborar uma análise sobre o “problema do ensino de Filosofia no nível médio de escolarização”, como o entendemos, e em cujo bojo encontramos, assim, a questão da formação docente.

Entretanto, como podemos mostrar, colher dados adicionais através de questionário submetidos aos professores, com o rigor desejado por um estudo dessa natureza, não nos pareceu uma empresa fácil para a conquista do êxito nas respostas, uma vez que observamos: 1. Os professores, na sua maioria, são pessoas muito ocupadas, pois distribuem as suas horas de trabalho em muitas instituições e, raramente dispõem de tempo extra para dedicar-se a preenchimento de questionários que caem em suas caixas de e-mails. 2. Muitos deles não veem com bons olhos esse tipo de estudo em termos de um retorno significativo ao seu trabalho, ou mesmo, segundo observações, alguns se sentem até desmotivados na profissão, desesperançosos ou desinteressados em buscar soluções já desacreditadas. 3. Os números que totalizam os docentes incluídos nas informações organizadas com os dados colhidos por este estudo não correspondem exatamente à realidade, pois, como afirmamos, há muitos docentes que são contados mais de uma vez na lista desses profissionais, pois suas presenças se dão em mais de um colégio e até em mais de um município por onde transitam semanalmente.

Objetivando inicialmente trabalharmos somente com os docentes atuantes no âmbito estadual, dispostos a participar da proposta, ampliamos essa população, uma vez que os primeiros se mostraram lentos para responder à nossa solicitação, em conformidade com prazo estabelecido para a devolução do questionário. Como o que nos interessava no estudo era trabalhar com "professores de Filosofia”, para entender melhor os problemas e questões que rondam a sua formação, não vimos qualquer empecilho de outros docentes, mesmo de outras regiões do estado também participarem. No conjunto dos participantes - alguns dos quais, como anunciamos, tendo 
aderido ao estudo de modo voluntário diante de nossa disposição em incluir outros interessados -, observamos a presença de alguns deles sem a formação no curso de Filosofia, seja na Licenciatura ou Bacharelado, o que entendemos ser isso o esperado, considerando os dados iniciais já mostrados. Tentaremos apreender as informações apresentadas nestas respostas, em nossas análises sobre a formação dos professores.

Contudo, feitas as ressalvas, passamos a nos preocupar, em seguida, com as contribuições que dos participantes pudemos colher a partir de um elenco de perguntas, a saber:

1. Formação acadêmica (contendo 10 perguntas);

2. Atuação profissional (contendo 07 perguntas); e, finalmente,

3. Informações teóricas - relativas às condições filosófico-pedagógicas vivenciadas por esses professores (contendo 07 perguntas).

É a partir dessas respostas que passo imediatamente às importantes observações capturadas da experiência viva, real, efetiva e vivenciada no cotidiano desses professores de Filosofia que atuam no ensino médio paranaense, particularmente, na região de Londrina (NRL). Assim, considerando os 14 participantes do estudo, observamos dois que não possuem a graduação em Filosofia, dado este satisfatório, uma vez que os números apresentados na Parte I do presente estudo já indicaram essa possibilidade, mesmo uma necessidade frente à urgência do provimento de professores nas vacâncias causadas pela falta de profissionais formados nos cursos específicos de Filosofia. Nesta amostragem, encontramos um perfil de professores interessados na continuidade dos estudos em vista da obtenção dos graus de especialistas e/ou mestres como busca necessária quanto às questões educacionais, cujo aspecto em sua formação nos cursos de Filosofia careceu de atendimento, segundo o posicionamento de alguns deles. Desse modo, dos 14 participantes, oito fizeram ou estão realizando estudos relacionados à Educação. Do grupo inteiro, observamos oito sujeitos que trabalham com outras disciplinas que não a Filosofia, estando ainda seis deles percorrendo diferentes instituições, com ênfase no trabalho em escolas públicas, embora haja quatro que atuam igualmente em escolas particulares. 
Chama a atenção o fato de que esses docentes têm que lidar com um grande número de alunos por classe, oscilando entre 30 e 45, aproximadamente.

Para pensarmos sobre o tema "formação de professores de Filosofia no ensino médio", vêm-nos à mente os “motivos" que podem ter favorecido esses profissionais a optarem por essa profissão e a se manterem nessa escolha durante a graduação e depois dela, mesmo sem os incentivos que desejariam ter encontrado na graduação. Assim, quanto às questões relativas à motivação para serem professores e ao preparo desses profissionais para efetivamente trabalharem no ensino médio com a disciplina de Filosofia, cumpre notar as suas respostas diretamente vinculadas à pergunta: Quais os motivos que o levaram a ser professor de Filosofia?

Assim, observamos que aos cursos de Filosofia chega um público cuja subjetividade apresenta forte tendência à docência, apresentando ainda elementos significativos para a realização pessoal e profissional. Dentre as justificativas apresentadas para a assunção da profissão, destacamos em primeiro lugar o gosto e a paixão pela disciplina (05); em seguida, é citado o desejo de se tornar professor desde muito cedo (05); depois, vem o empenho na realização dos objetivos de levar os alunos a questionar, refletir, investigar, criticar, etc. (04); a necessidade de trabalho (02); a possibilidade de comunicação e compartilhamento (02); dentre outras motivações. Apareceu também a menção da disciplina de Filosofia no ensino médio como incentivadora dos estudos posteriores (02) e a presença de professores que marcaram a disciplina e, por isso, fomentaram neles a docência (02). Também notamos que muitos dos professores ofereceram mais de uma boa razão para terem se tornado professores de Filosofia.

Tendo essas ideias assim explicitadas, pensamos na importância de aferir como a "vontade de se tornar professor foi sendo construída e/ou reforçada". $\mathrm{E}$ assim investigamos em quais momentos os saberes referentes à educação foram nutridos. Perguntamos primeiramente se eles participaram de projeto(s) de pesquisa ou de extensão com temática filosófico-educacional durante a graduação e quais os temas/títulos de TCC (Trabalho de Conclusão de (urso), monografia, dissertação ou tese realizadas. A participação em projetos, a nosso ver, propicia uma situação favorável ao entendimento das 
questões filosófico-educacionais, possibilita a apreensão do vocabulário e experiências na área, promove o conhecimento de autores referências nesses estudos, enriquece e mobiliza o jovem para o aprofundamento dos estudos concernentes a esses temas, motivando-os gradativamente ao exercício da docência na disciplina de Filosofia. Com respeito aos TCCs, a nosso ver, seguem-se os mesmos argumentos apresentados no item "projetos", com o acréscimo de que, no desenvolvimento e elaboração desses trabalhos, há possibilidades de um importante envolvimento e acompanhamento de um professor do curso por um bom período de atividades, e a realização de uma pesquisa já mais amadurecida, considerando-se os estudos e as experiências acumulados durante todo o curso de graduação. Nesse sentido, a expectativa de que aqueles interessados na docência - e, especialmente, em função das características dos cursos de Licenciatura - teriam a oportunidade de realizar pesquisas vinculadas a temas sobre as diversas relações possíveis da Filosofia e da Educação. Contudo, isso foi grandemente enfraquecido pelos dados obtidos.

As respostas podem ser conferidas observando-se a discussão que passamos a apresentar a seguir. No tocante aos projetos, dentre os 14 sujeitos participantes, seis não tiveram a experiência apontada, na graduação; apenas quatro responderam positivamente; três citaram trabalhos cujas temáticas não manifestam aspectos filosófico-educacionais explícitos; e um não respondeu. Um dos participantes citou projeto relativo ao PIBIC/CNPq, e um outro, o PIBID/Filosofia. Numa visão geral, percebemos um índice baixo de respostas positivas com respeito ao quesito investigado. Em relação aos TCCs, dentre os títulos dos 14 trabalhos listados, apenas um explicita claramente um tema relativo à Educação analisada à luz da Filosofia. Os demais tratam de temas relativos a conteúdos estritamente filosóficos, com exceção de dois, que se distanciam totalmente da disciplina de Filosofia relacionada ao exercício da docência. Contudo, percebemos um crescente interesse no aprofundamento e investigação nas temáticas filosófico-educacionais, à medida que os profissionais galgam estágios formativos em vista da obtenção de maior titulação. Assim, podemos indicar oito docentes que podem estar nessa condição contra outros cinco que se mantêm pesquisando temas 
específicos da área da Filosofia propriamente dita ou, até mesmo, permanecendo distantes dessa preocupação. Contudo, apenas um dos participantes se mantém claramente com o enfoque filosófico-educacional.

Continuando na direção de obter mais subsídios em vista da aferição sobre a qualidade da formação que esses professores experimentaram para um melhor "exercício da docência em Filosofia", perguntamos sobre quais os conhecimentos relevantes para a sua atuação docente, obtidos durante a formação e o que teria faltado.

Quanto aos "conhecimentos relevantes oferecidos na graduação que contribuíram com a docência", a maioria aponta para os conhecimentos filosóficos específicos; três participantes não responderam; um indica a Pesquisa como tendo sido a tônica mais relevante do curso; três apontaram para disciplinas de perfil mais pedagógico; e um deles salientou o significativo “modelo do professor” a ser seguido pelo graduando. Na questão relativa à carência de conteúdos que poderia ser apontada na Licenciatura, foi salientada, por três manifestantes, a falta ainda de outros conteúdos filosóficos que não foram oferecidos; dois não responderam; mas a maioria apontou como elementos negativos de sua formação: a falta de conhecimentos relativos às matérias pedagógicas e à pratica em sala de aula; o excesso de relatórios que elaboraram em detrimento do contato com a sala de aula; a exagerada ênfase na pesquisa em prejuízo à formação docente; a indisposição de alguns professores de tratarem da educação básica; e a separação do mundo da universidade e o mundo do ensino médio.

As sugestões e críticas presentes nas manifestações dos professores nos levam a notar que é preciso tratar mais diretamente da disciplina de Filosofia no ensino médio, nos cursos de formação docente, pontuando, sobretudo, alguns importantes aspectos. Primeiramente, todos os participantes confirmam a importância de um trabalho sério e aprofundado dos conteúdos filosóficos específicos, o que é, inclusive, indicado por alguns deles, como tendo sido essa a sua experiência, mesmo assim ficando carente de tratamento ainda mais completo. Em segundo lugar, percebemos a necessidade de que sejam veiculados nos cursos de graduação aqueles conteúdos filosóficos produzidos em torno do "problema da educação", ou 
seja, é sugerido que não sejam ignorados o que as grandes mentes da história da filosofia pensaram, criticaram e apontaram em referência às temáticas sobre a formação humana e outras afins. Finalmente, torna-se claro que os aspectos didático-pedagógicos, os conhecimentos da prática e da realidade escolar devam ser oferecidos a contento aos docentes, constituindo-se numa bagagem suficiente para a sua formação. Outra questão a ser enfatizada é a carência de estudos e pesquisas realizados durante o curso norteados pelas questões supracitadas. Observamos ainda que os sujeitos apontam para o problema pernicioso do preconceito sobre essas questões e interesses, o qual pode ser encontrado explicita e intensamente já na graduação, situação em que alguns deles depararam-se, havendo aí professores e mesmo outros jovens que expressavam forte indisposição ao tratamento desses conteúdos.

Para encerrar esse rol de perguntas relativas ao entendimento dos participantes quanto aos problemas da sua Licenciatura e os avanços percebidos durante esta etapa da sua formação, perguntamos se ele ou ela julga a Filosofia e a Educação como campos interligados e quais os filósofos estudados, segundo sua perspectiva, que contribuem para a Educação.

Observamos que a maioria não nega, e mesmo enfatiza, as relações estabelecidas entre a Filosofia e a Educação, citando, como exemplos, os nomes mais diversos dos grandes filósofos presentes na história da Filosofia. Podemos apontar, inclusive, para a clareza com que os professores se manifestaram sobre essas relações e a forma precisa, peculiar e lógica dos nexos apresentados. Assim, podemos ilustrar com algumas das afirmações: "A Filosofia pensa a finalidade da Educação na formação humana, integral, Paideia" (sujeito 01); "A Filosofia está relacionada, em muitos momentos, à formação humana [...] Sair da caverna [referindo-se à Alegoria de Platão] envolve um processo educativo, de condução" (sujeito 02); “Não é preciso compreender a realidade sem lançar mão de ideias, sem a atividade filosófica. Assim como não é possível compreender/praticar a educação sem buscar os fundamentos da própria ação educacional [...]” (sujeito 03); “[...] não existe forma de buscar o conhecimento sem reflexão, papel que a filosofia desempenha atuando de forma que o aluno busque reflexão em todas as áreas da educação e do próprio conhecimento científico" (sujeito 05); “A 
educação casa com todas as formas de saber, sobretudo, traça ligações estreitas com a filosofia por ter como objeto de estudo o desenvolvimento do pensamento humano. Os problemas da educação são de grande relevância filosófica” (sujeito 06); “[...] a vértebra da filosofia sempre foi vinculada à educação, em um sentido formativo mais amplo, e isso se remete desde Sócrates até a contemporaneidade” (sujeito 08); “[...] a filosofia, longe de objetivar a formação do senso crítico e de pessoas éticas (coisas que outras disciplinas podem também bem fazer), tem precipuamente a finalidade de nos ajudar a viver melhor. Nesse sentido, a contribuição da filosofia envolve uma formação que extrapola aquele caráter "disciplinar”, enquadrado dentro de fronteiras bem definidas [...] aprendizado e vivência, educando e educador tem um vínculo mais do que formal” (sujeito 09 - grifos nossos); “[...] esse conhecimento [o filosófico, desde as suas origens] [foi] mediado, discutido e difundido (como no método socrático). A Educação faz essa ponte entre o refletir [a construção do saber] e saber [conhecimento adquirido]. Obs.: No curso de Filosofia não foi dado enfoque à Educação. Fui aprender a importância dessa relação entre Filosofia e Educação já atuando na profissão" (sujeito 10); “Não existe a possibilidade de separar os temas filosofia e educação, pois se cruzam desde a Grécia Antiga, tratando a origem do conhecimento e como o homem pode absorver esse conhecimento" (sujeito 11); “A filosofia se preocupa com a educação e, principalmente, como ela é passada para os outros. É de extremo interesse da filosofia que existam seres críticos, pensantes e com conhecimento" (sujeito 12); “[...] toda Filosofia consiste na indicação de um caminho possível para a formação humana, portanto, penso que a Filosofia e a Educação mantêm relações estreitas que não deveriam ser desconsideradas" (sujeito 13); e, finalmente, “[...] o questionamento, a reflexão e a busca pelo conhecimento que são atitudes fundamentais para a filosofia também o são para a educação" (sujeito 14). Contudo, quanto aos filósofos que podem ser citados como aqueles que melhor contribuem para abordarmos o problema da educação, há, para alguns, uma ampla e irrestrita lista de nomes, da qual podemos situar aqueles mais célebres e clássicos junto aos não tão reconhecidos, pelo menos comparativamente aos primeiros, ou mesmo aparecem personalidades de 
outros campos do conhecimento. Nota-se no geral, variados critérios adotados pelos professores para realizarem essa seleção de nomes.

Buscamos, a seguir, saber ainda quais seriam as suas maiores dificuldades e limites encontrados para uma razoável atuação profissional, devendo ser citadas em ordem hierárquica decrescente, isto é, do mais importante para o menos importante.

Podemos agrupar os problemas mencionados pelo menos em três categorias, a saber:

1. Aqueles que dizem respeito a questões institucionais e relativas às políticas públicas e orientações pedagógicas, sendo as mais destacadas:

a) Primeiramente, há necessidade de boa estrutura, em geral, adequada aos objetivos da disciplina e do trabalho planejado pelo professor; há falta de material didático; e presença de bibliotecas precárias nas escolas;

b) há um contingente excessivo de alunos por turma;

c) Há muitas funções extracurriculares e burocráticas alheias ao trabalho imediato do professor no exercício de suas atividades em sala de aula;

d) há muita pressão da escola para a aprovação dos alunos e a utilização de estratégicas de recuperações que interferem na qualidade do ensino;

e) há, com considerável frequência, muitas mudanças de orientações e diferenciadas metodologias apresentadas aos professores;

f) há, ainda: falta de políticas mais eficientes; falta de ética e muito corporativismo nas escolas; e um abandono do ensino noturno.

2. No que concerne aos próprios professores, foram citados os seguintes problemas:

a) Em primeiro lugar, há falta de maior apoio pedagógico, carência de linguagem e técnicas mais adequadas para o trabalho docente, sendo tudo isso traduzido, no geral, como uma necessidade de maior e melhor formação continuada dos professores; 
b) em seguida, são indicados os problemas implicados na pouca valorização social da profissão, falta de um plano de carreira mais bem definido e de um salário decente aos professores;

c) em terceiro lugar, são apontados os problemas da insuficiência das horas-atividades e horas-aulas que permitam tanto o aprimoramento dos profissionais e tempo para estudo, como para darem conta dos conteúdos a serem trabalhados com os alunos em sala de aula. Foram apontados os problemas gerais já citados e que impedem ao professor ter tempo suficiente para estudar e preparar as aulas.

3. No tocante aos alunos, destacamos:

a) Em primeiro lugar, dois grandes conjuntos de problemas:

1) indisciplina e violência;

2) apatia, desinteresse e muita desmotivação frente ao conhecimento ${ }^{4}$;

b) em seguida, foram citados: o desrespeito e descompromisso do aluno e da família em relação aos estudos e atividades necessárias à obtenção dos conhecimentos na disciplina; há pouca disposição dos alunos para a leitura, os quais vêm apresentando um baixo nível de pré-requisitos necessários ao sucesso esperado.

Frente a tais informações, perguntamo-nos se esses professores foram bem preparados durante a graduação para o enfrentamento desses problemas. Além disso, observamos o quão importantes podem ser as suas contribuições no âmbito escolar mais geral, enquanto filósofos, ilustradas por algumas das situações apresentadas acima, como nas questões concernentes ao item 1e e 1f, por exemplo, apenas para citar alguns. Em relação aos inúmeros

\footnotetext{
${ }^{4}$ Segundo exposição de um docente do CEEBJA (Centro Estadual de Educação Básica para Jovens e Adultos) - Londrina, na sessão dos Relatos de Experiência da ANPOF - 2012, observamos outros problemas apontados, os quais são próprios das classes compostas pelos alunos adultos e que devem ser enfrentados pelos professores de Filosofia, como: 1. heterogeneidade do público escolar, constituída pelas minorias étnicas, pessoas com necessidades especiais, adultos com experiência escolar problemática como a contínua repetência, pessoas de idades variadas, às vezes, bem avançada, etc. 2. desinteresse pelo conhecimento em si mesmo, uma vez que frequentemente são movidos à escola na busca pela certificação ou tendo em vista uma melhor remuneração na aposentadoria ou, ainda, o fazendo pela exigência do empregador, e assim por diante. 3. Experiências escolares frustradas e poucas habilidades desenvolvidas satisfatoriamente para o bom andamento da disciplina de Filosofia, como habilidades de leitura e de escrita, domínio da língua em geral para a comunicação e elaboração do seu pensamento e entendimento do vocabulário filosófico, por exemplo, dentre outros problemas.
} 
problemas que orbitam na esfera da prática docente, cumpre-nos lembrar a percepção de Gallo (2012, p. 02):

Penso que os problemas práticos do professor de Filosofia não sejam diferentes dos problemas práticos de qualquer professor [...] Hoje, especialmente, a dificuldade de leitura por parte dos estudantes, um desinteresse generalizado pela escola e por aquilo que ela oferece. A questão é que o professor não pode idealizar a escola, idealizar o aluno. As grandes críticas que vemos hoje à escola devem-se ao fato de que ela não cabe naquilo que é idealizado pelos professores. Talvez a maior qualidade de um bom professor seja seu senso de realidade e a capacidade de atuar nas condições reais da escola. Diria, então, que a questão está na criatividade e na capacidade de adaptação do professor, que precisa encontrar, em cada turma que leciona, o tom correto, a forma de penetrar em seu universo. Para isso, é necessário ter um repertório bastante amplo, do qual o professor disporá na medida das necessidades de cada situação (grifos nossos).

É preciso, antes de qualquer coisa, segundo o autor, que o professor tenha tido um "amplo conhecimento da Filosofia" - o que permitirá a ele orientar-se nela e no pensamento presente em sua história -, adicionando criatividade na utilização desta bagagem teórica e um conhecimento adequado da realidade escolar, para que não a idealize e se frustre quando nela estiver atuando. Assim, “[...] a universidade pode preparar o futuro professor não para antecipar ou resolver de antemão os problemas práticos que aparecerão, mas para que ele saiba identificar os problemas e tenha estofo e bagagem para resolvê-los, na medida em que aparecerem" (GALLO, 2011, p. 4).

Observando tais indicações e diante do quadro geral aqui apresentado, perguntamos se os participantes deste estudo se julgam bem preparados para exercer as suas atividades profissionais como professor de Filosofia no ensino médio, nove docentes disseram que "sim", dois afirmaram que "não", e três responderam de forma evasiva ou ambígua. Aqueles que se posicionaram positivamente justificaram sua posição da seguinte forma:

1. "[Sinto-me bem preparado] Mais por conta da própria prática do que por preparação da universidade na licenciatura!!!” (sujeito 02).

2. "Apesar da pouca experiência de "sala" no ensino de filosofia acredito ter um conhecimento teórico significativo 
e uma experiência educacional (acadêmica), em outras áreas que me garantem tal competência" (sujeito 03).

3. "Porque vivo constantemente me atualizando, pesquisando, assim como sempre estou me colocando no lugar dos estudantes e pensando com eles os conteúdos que valem a pena ser estudados; além de acreditar que a filosofia no ensino médio é possível" (sujeito 04).

4. "Acredito ter tido uma boa formação, tenho compromisso com as atividades da docência, gosto do ambiente escolar, estou sempre tentando atualizar meus conhecimentos, gosto do que faço (minha opção por filosofia pode ter tido alguns fatores determinantes que me influenciaram na hora de minha escolha, mas atuar como professor sempre foi, desde a infância, meu desejo e depois de adulto, minha livre decisão)" (sujeito 07, grifo nosso).

5. "Primeiramente, porque estou em constante formação intelectual para o cumprimento das minhas funções como educador, buscando conhecimentos e práticas que me auxiliam no exercício de minha atividade. Considero $a$ formação do docente parte fundamental para uma substancial melhora da Educação, formação esta pouco estimulada, principalmente pelos órgãos responsáveis (como fato poderia citar o não incentivo para a produção científica dos professores, nem licença para que os professores façam mestrado, ou incentivos que visassem uma melhor preparação dos profissionais da educação) a não ser cursos organizados pela própria Secretaria de Educação, previstas em calendário (como a semana pedagógica) que, sinceramente, não contribuem em absolutamente nada na formação dos professores. Mesmo os cursos preparados pelos Núcleos Regionais, com proposta de trabalhar as disciplinas especificamente, mesmo esses cursos, em minha opinião, contribuem muito pouco para a formação do profissional. Mas, além desses cursos, estou buscando formar-me, no Mestrado, por exemplo, que optei em fazer na Educação para exatamente poder expandir meus horizontes sobre o tema" (sujeito 08, grifos nossos).

6. "Existe em mim doação. Eu faço o que faço porque gosto. Preocupo-me sempre em melhorar, de dar o melhor de mim e percebo que isso faz a diferença, pois o dia a dia em sala de aula anda bem desestimulante. 0 que fica, o que faz diferença é como escolho atuar. Não vou à sala de aula só passar conteúdos. Assim os alunos poderiam ler o mesmo em casa e não precisariam da minha atuação. Quando me é permitido, gosto de levar a diferença estimulando o raciocínio" (sujeito 10, grifos nossos). 
7. "Nos últimos oito anos tenho feito um bom trabalho [em minha escola], com vários alunos gostando muito das aulas, e indo bem nas avaliações, como ENEM e vestibular" (sujeito 11, grifos nossos).

8. "Embora tenha encontrado as dificuldades descritas, creio que o trabalho é realizado de maneira razoável e satisfatória" (sujeito 13).

9. "Tenho uma boa fundamentação teórica e vontade de ensinar" (sujeito 14).

Quanto àqueles que se posicionaram negativamente, assim se justificaram:

1. "Tenho buscado constantemente a identidade que me satisfaça como professora de Filosofia. Não tinha e talvez ainda não tenha muito clara tal função. Quais minhas possibilidades e limitações. No entanto, a cada ano, graças ao meu estudo, tenho adquirido cada vez mais confiança em meu trabalho. Penso que a profissional não é distinta da pessoa que sou na questão de valores e tudo mais. $O$ que me falta ainda descobrir e melhorar é a forma de comunicar tais valores. Estudando Dewey me percebo no caminho de ser mais que uma professora que transmite conteúdos acadêmicos. Busco ser uma educadora. Pensando na Filosofia, não dá para exigir menos que isso" (sujeito 01, grifos nossos).

2. "Gostaria de mais tempo para preparar as aulas, me inteirar sobre novos assuntos" (sujeito 06).

Por esses posicionamentos, observamos respostas embasadas numa dedicada reflexão e busca imperativa sobre o "ser professor", e mais, "ser professor de Filosofia", como algo que se coloca necessário na vida desses profissionais. Acompanha essa postura a análise crítica dos elementos impeditivos que se encontram no entorno das suas ações profissionais, como: a falta de mais tempo para o preparo de aulas, o pouco investimento e incentivo por parte das universidades quando de sua formação nos cursos de Licenciatura, daí resultando, quem sabe, o que apontam como dificuldades em se entenderem, de fato, como um(a) professor(a) ou um(a) educador(a). Isso ainda pode ser agravado pelo pouco estímulo das autoridades competentes em realizar bons cursos de formação continuada aos professores de Filosofia e de lhes oferecer melhores condições de aprimoramento, como 
horas de trabalho destinadas à pesquisa, por exemplo, além de outras necessidades.

Como elementos explícitos citados, destacamos: o empenho diuturno da maioria para o seu aperfeiçoamento profissional, através de iniciativas próprias, pois motivados pelo gosto ao trabalho, de busca por cursos de formação, de ampliação de leituras e incorporação de novos autores às suas experiências, muitos dos quais são desconsiderados nos cursos de graduação (pois não vistos como "filósofos" propriamente ditos ou teriam sido interpretados como "intelectuais de menor calibre"). Aparecem, ainda, os esforços em realizar pesquisas e em avaliar constantemente os conteúdos ensinados, considerando sua validade e importância efetiva aos alunos. Pelo menos dois destacaram a Filosofia como sendo uma disciplina que necessita especialmente dessa atenção e acompanhamento constantes. Assim, encontramos, por exemplo, a seguinte afirmação: “Pensando na Filosofia, não dá para exigir menos que isso" (sujeito 01). No conjunto dos participantes, notamos pelo menos 05 afirmativas explícitas pelo gosto em ser professor ou educador, pelo compromisso que a profissão exige, pela busca da melhoria da educação através do seu trabalho, e assim por diante (sujeitos 01, 07, 08, 10 e 11). Dos nove participantes, três destacaram a sua excelente formação e consistente bagagem teórica adquirida quando ainda estudantes (sujeitos 03, 04 e 14).

No que concerne ao bom preparo do professor, Gallo assinala:

[...] o professor não se forma apenas na universidade, ele não sai pronto. Ele precisa sair com uma boa base, mas é sendo professor que ele se torna, de fato, professor [...] há muito da prática docente que só aprendemos na própria prática docente. Não adianta nos dizerem como é, como se faz ou nos encherem de milhares de horas de estágios de observação da sala de aula. Isso tudo é importante, na justa medida, mas nada disso nos prepara em absoluto para os desafios da sala de aula. Precisamos chegar ao ensino com uma boa bagagem, para que possamos, na prática, aprender a lidar com essa bagagem. Ninguém pode fazer esse percurso por nós, por cada um de nós (GALLO, 2011, p. 3).

A última parte da investigação apresentada aos professores tenta apreender, com mais agudeza, o seu efetivo exercício em sala de aula. Assim, perguntamos: Os conteúdos que você ensina lhe parecem atrair a atenção dos 
seus alunos ou você diria que seriam irrelevantes segundo a manifestação deles próprios?

Neste quesito, observamos duas posturas básicas apresentadas de forma quase equilibrada: uma se assenta numa visão negativa que os alunos teriam sobre a disciplina de Filosofia, por exemplo, que os conteúdos seriam irrelevantes, pouco atrativos, muito abstratos, muito novos e, por isso, estranhos, faltando-lhes, contudo, segundo alguns professores, o hábito dos conhecimentos clássicos, uma cultura mais sofisticada e um maior comprometimento e incentivo dos pais. A outra visão mais positiva aposta na necessidade de "novas abordagens", métodos de ensino mais atrativos aos adolescentes, um conteúdo apresentado que possibilite o entendimento de sua realidade e que eles percebam que os conceitos filosóficos têm implicações e consequências em suas vidas. Um professor insistiu na necessidade de atualização constante do professor e na abordagem interdisciplinar como sendo boas saídas para o problema, enfatizando que a Filosofia não deve trabalhar de forma isolada na escola. Dois professores não apresentaram respostas claras sobre o assunto ou aparentam não possuir uma opinião formada acerca do problema.

Continuando a apresentação de perguntas que constituem a terceira e última parte do questionário, a saber, o que você ensinaria e que não está contemplado nos conteúdos programados na disciplina de Filosofia?, obtivemos posicionamentos que podem ser assim apresentados: um professor não respondeu, mas sete professores citaram disciplinas e/ou assuntos mais tradicionais que, a seu ver, estariam faltando ou enfatizados nas propostas curriculares. Consideramos, ao lado das sugestões de Lógica, Antropologia Filosófica, Psicanálise, Filosofia da Tecnologia, Filosofia e Ética Ambiental, Bioética, etc., aqueles que disseram que ensinariam a tragédia grega, por exemplo, e os autores contemporâneos, os mais atuais, e assim por diante. No entanto, observamos a sugestão de dois participantes que insistiram nos temas da Filosofia vinculados "[...] a algumas questões um pouco mais próximas do cotidiano dos (meus) alunos" (sujeito 08) como os assuntos sobre a internet, cinema, literatura e música ou temas que tragam uma questão "seminal", a saber, "[...] o que é a vida boa? O que podemos esperar e fazer 
de nossas vidas?" (sujeito 09). Um dos professores insiste que o problema da falta de motivação para os estudos na disciplina não permite grandes inovações, uma vez que estas seriam inócuas. Em suas palavras: "Parafraseando Einstein, o problema é que você não pode ensinar nada a ninguém, mas ajudar as pessoas a descobrir por si mesmas, desde que elas queiram. Mas o problema é justamente esse. Eles não querem" (sujeito 03). Essa posição é justificada pela crença de que, sendo a "filosofia uma atividade", exige disposição e ação de pensar por si mesmo. Quatro professores argumentam que o problema do ensino de Filosofia não estaria nos conteúdos, uma vez que estão adequados, ricos em possibilidades; ainda observam que a Filosofia não depende essencialmente de teorias e conteúdos pré-estabelecidos, visto ser atividade.

Os participantes do estudo contribuíram a seguir frente à questão: Quais as maiores dificuldades que os alunos encontram na disciplina de Filosofia? Notamos, em primeiro lugar, uma frequência significativa nos problemas referentes a dificuldades de linguagem, vocabulário, interpretação, leitura e escrita (sujeitos 02, 03, 04, 07, 08, 09, 11 e 14). Em segundo lugar, destacamos o que foi designado por carências culturais que os alunos têm revelado; também, o que foi apontado como dificuldade em mudar as concepções pré-estabelecidas, uma vez que apresentam, por exemplo, “[...] limitações devido a posturas religiosas extremadas [...]" (sujeito 07) ou por serem pessoas que "[...] estão acostumados a ter tudo pronto, é a geração Google" (sujeito 06; mas, aqui também podem ser citados os sujeitos 04 e 05). Curiosa foi também a menção dada à dificuldade que a própria disciplina em si mesma oferece aos alunos. Assim, imputam à Filosofia os qualificativos de disciplina difícil (sujeito 07), talvez inútil (sujeito 10), muito teórica (sujeito 12), não compreendem a sua relevância (sujeito 14). A falta de concentração, a indisciplina, a imaturidade, as brincadeiras em sala de aula foram outros empecilhos mencionados (sujeitos 01, 02, 07 e 13). Uma interpretação interessante foi a apontada por um dos professores (sujeito 09), que se referiu à existência de um novo paradigma na atualidade em que o perfil da sociedade e de suas instituições deve se adaptar. Então, argumenta: "[...] não sabemos [mais] qual é a função da escola e quais as demandas que 
realmente são de sua competência resolver [...] o que é a escola? O que ela realmente deve ensinar?" Outro fator dificultoso é a "[...] super-proteção que [na atualidade] é garantida ao adolescente, mas que vem gerando uma situação ambígua, pois, enquanto apresentam um baixo nível de responsabilidade [devido a isso], são deixados a experimentar situações sem preparo adequado e cuidadoso" (sujeito 01). Foi ainda apontado o pouco tempo de aula de Filosofia como um fator limitante ao aluno (sujeito 04).

Focalizando tais apontamentos acerca dos alunos, suas dificuldades e os desafios que colocam aos seus professores, observamos que na formação docente deve ser considerado, mais incisivamente, o trabalho docente como aquele que se localiza num contexto para além daquilo que concerne à prática em sala de aula, especificamente, ou às atividades disciplinares. Sem esta consciência, fica difícil ao professor se sentir confortável no campo complexo de forças em que se encontra ao realizar o seu trabalho. Como salienta Marshall (1977, p. 14-15):

[...] cada professor funciona em uma situação complexa. Ele trabalha diretamente com alunos que diferem uns dos outros de muitas maneiras. Cada um é um feixe único de habilidades, em parte herdada e em parte aprendida. Cada um vem à escola com uma experiência social única, com raízes de seu lar e família, de seus semelhantes, de sua comunidade e de sua sociedade de forma geral. Eles possuem algumas ideias do que é importante para si e o mesmo pensam seus pais, amigos e pessoas de sua comunidade. Está também numa escola que o submete a um conjunto de expectativas geralmente formalizadas - um curriculum destinado a ajudá-lo a obter mais conhecimento, estimular suas habilidades, melhorar seu pensar - em resumo, crescer e se desenvolver como uma pessoa madura (grifos nossos).

É evidente que devemos considerar quais as ideias do que parece importante ao aluno, segundo a sua própria visão, a dos seus pais e a da comunidade em que vive. Muitos deles, no entanto, talvez jamais tenham entrado antes em contato com uma experiência filosófica. Ou, no mesmo caso, tenham tido tal experiência, quem sabe se esta fora construída com elementos desarticulados e buscados nas mais diversas e desconectadas origens?! Como poderia ser, então, estimulado para uma reflexão mais rigorosa?! Contudo, "O professor está tratando com um educando que por sua vez o está atormentando com perguntas sobre si mesmo, sobre seu valor, 
sobre o significado de suas experiências e das coisas que estão acontecendo ao seu redor" (MARSHALL, 1977, p. 12-13). Eis uma grata oportunidade para trazê-lo às respostas que a história do pensamento o permite acessar. No entanto, algo que não pode ser desconsiderado nesse contexto é que

O educando está sempre sujeito a um arranjo confuso de forças, influências e exigências que o bombardeiam, de uma dúzia de direções ao mesmo tempo. Elas vêm de muitas fontes - sua formação familiar, sua comunidade, seu grupo de iguais e particularmente, suas expectativas na escola. Além disso, os desejos, aspirações e problemas do aluno são sempre os determinantes de suas motivações, interesses e empreendimentos (MARSHALL, 1977, p. 13).

Pelas respostas dos professores, observamos claramente o conjunto desses problemas presentes nas referências que fazem das suas experiências. Assim, diante desse quadro, perguntamos: Quais os objetivos da disciplina de Filosofia na formação do jovem? Coloque-os em ordem de importância do mais ao menos importante. Essa pergunta, a nosso ver, poderia oferecer um sentido mais amplo do trabalho da disciplina segundo a ótica dos professores, integrando as atividades, as propostas, os conteúdos com os objetivos estabelecidos, num esforço de realização formativa consoante ao jovem do ensino médio, o qual, não obstante as motivações positivas que apresentam, manifestam também alguns problemas passíveis de solução, mesmo sendo isto possível em médio prazo. O resultado dos posicionamentos dos professores diante dessa pergunta pode ser observado numa oscilação ora quanto às suas crenças de que ela oferece uma rica perspectiva para o desenvolvimento dos jovens, ora fazendo com que recuem, dada a situação escolar caótica em que se encontram com alguma frequência.

Dentre as várias sugestões sobre as contribuições da disciplina na formação do jovem, notamos que os participantes apostam, em primeiro lugar, no papel da Filosofia em: 1) promover a construção de uma vida melhor, permitindo um entendimento e uma percepção mais clara do mundo, o que é possibilitado pelo exercício da reflexão e pela reaprendizagem sistemática do mundo. Em seguida, acreditam na 2) promoção do pensar melhor, na conquista da boa argumentação e na 3) realização da autonomia dos sujeitos, tornando-os capazes de desfazer preconceitos e prejuízos 
causados pelas ideologias que podem dominar as suas mentes, dentre outros problemas. Na sequência, notamos uma frequência de respostas que incidem sobre a 4) capacidade da Filosofia em promover as habilidades de criticidade e de reflexão que permitem o diálogo, a liberdade de pensar e de se posicionar diante do mundo. Apostam ainda na 5) construção da cidadania, da ética e da democracia como potencialidades da Filosofia na formação dos sujeitos. 6) $O$ gosto pelo conhecimento, permitindo a conscientização sobre os limites e possibilidades do conhecimento humano, é outra das tarefas que, na visão dos professores, pode ser desenvolvida pela Filosofia.

Não obstante as importantes percepções sobre as tarefas da disciplina de Filosofia no ensino médio indicadas pelos professores em meio às dificuldades gerais salientadas e as suas sugestões, observamos uma busca imperativa por melhores crenças sobre a disciplina e sobre o seu trabalho. Revelam a necessidade de concepções mais bem construídas e que the permitam tomar rumos mais consistentes para o desenvolvimento de suas atividades docentes específicas, ao mesmo tempo sentindo a pertinência de seu trabalho nas instituições formativas em que atuam. Nesse particular, trazemos Gallo, mais uma vez, que alerta:

[...] há uma certa dificuldade dos estudantes em assumir uma concepção de Filosofia (o que chamei, antes, de orientar-se no pensamento), na medida em que nossos cursos, mais comprometidos com o bacharelado do que com a licenciatura [...] não investem nisso. E isso dificulta, em muito, a atuação do professor, pois, para ensinar Filosofia é preciso colocar-se na Filosofia, movimentar-se com desenvoltura por sua história. Assim, na dificuldade de uma visão mais clara, eu diria que predomina uma concepção da Filosofia como formação crítica, às vezes uma visão da Filosofia como História da Filosofia, que mais dificultam do que ajudam a produzir uma boa aula de Filosofia (GALLO, 2011, p. 04).

\section{Discussão Sobre os Resultados Obtidos e Encaminhamentos Finais}

Tendo já realizado observações, a nosso ver importantes, ao longo da apresentação dos dados relatados, resta-nos apontar a seguir algumas outras considerações que nos ajudam a inter-relacionar esses dados com algumas outras ideias, em vista da promoção de uma interpretação e compreensão 
mais bem balizada e articulada, arriscando sugerir algumas saídas para o "problema do ensino de Filosofia".

Embora observemos as importantes e ricas contribuições oferecidas pelos professores neste estudo, os quais, de uma forma geral, se mostram preocupados em compreender o seu lugar na escola, a sua identidade como profissional e o sentido do seu trabalho, há urgência em algumas definições que envolvem essa atividade. Como nos admoesta Gallo:

[...] penso que o trabalho agora é ainda maior, pois temos que garantir que a Filosofia seja ensinada efetivamente e o seja de modo significativo. Se não conseguirmos provar, com um bom trabalho que a Filosofia é uma contribuição importante para a formação dos jovens brasileiros, ela será retirada. E aí talvez não tenha volta possível ... (GALLO, 2011, p. 1).

Frente aos dados aqui elencados e discutidos, observamos ainda que muitos dos professores em exercício têm consciência das carências em sua formação para a docência, queixam-se da falta de bons cursos de capacitação e tomam iniciativas individuais na busca por essa complementação na pesquisa e na pós-graduação, especialmente aquelas vinculadas aos Departamentos de Educação das universidades, o que nos parece ser, entretanto, um bom expediente. Assim, admoestados pela urgência que a situação impõe, a expectativa é que os cursos de formação em Filosofia ofereçam a partir de agora maiores possibilidades para o atendimento dessa clientela, que, inegavelmente, já chega à graduação com esse interesse, segundo o presente estudo, configurando-se esse fato em fator positivo merecedor de consideração. Contudo, observa Gallo (2011, p. 3):

De forma geral - e aqui corro o risco de toda generalização nossos cursos nunca se esforçaram, de fato, para formar professores de Filosofia para o Ensino Médio. Primeiro, porque não havia aulas; depois, porque elas eram escassas. Mas, também, porque em larga medida os departamentos de Filosofia pensavam que sua função era ensinar Filosofia; ensinar a ensinar seria a tarefa de pedagogos, dos departamentos de Educação. Vi isso em algumas universidades em que trabalhei e em muitas universidades que visitei e penso que seja um completo equívoco. A formação do professor de Filosofia - e penso que isso possa ser estendido a outras disciplinas - não pode dissociar o conhecimento específico da Filosofia do conhecimento do campo 
educativo. É preciso que um atravesse o outro, que um contamine o outro. [...] é necessário que ele [o professor] se preocupe também em como [um determinado] tema pode ser trabalhado com um adolescente no Ensino Médio. Porque ensinar neste nível não pode ser uma reprodução direta de como se ensina na universidade. Se há saberes pedagógicos específicos que o licenciando em Filosofia vai aprender com o campo da Educação, isso não significa que os professores de Filosofia possam se descomprometer com a tarefa do ensino da Filosofia (grifos nossos).

Essas noções do "ensinar Filosofia" entendidas por alguns como sendo uma tarefa mais próxima à dos Bacharelados, e a do "ensinar a ensinar Filosofia”, mais adequada às funções das Licenciaturas, provocaram discussões acirradas durante as reivindicações que antecederam o estabelecimento da obrigatoriedade da disciplina no ensino médio. Muitos profissionais da área, por se sentirem mais aproximados da primeira noção, mostravam-se inclusive, contrários ou indiferentes ao retorno obrigatório da Filosofia. Não sendo o objetivo do presente estudo analisar a oscilação entre essas diferentes posições e as suas motivações, cumpre-nos, todavia, assinalar o esforço sustentado por muitos dos professores de Filosofia - que estão hoje indo às escolas demonstrando uma sensação de que carregam consigo uma carência formativa, indisposição ou desconforto em ensinar aos jovens, o que reforça um argumento em favor de que sejam estabelecidas outras medidas para uma proposição diferenciada na formação docente nos cursos de Licenciaturas em Filosofia. É justo, contudo, também notar que muitos professores confessam ter conseguido resultados exitosos graças mesmo à formação que tiveram nas universidades ou à busca constante que impetram para o seu próprio aprimoramento.

Embora a Filosofia tenha reconquistado o espaço formativo nas instituições formais de ensino, tendo imposto uma situação desafiadora aos profissionais envolvidos que se vêm agora obrigados a tratar do assunto e a tomar decisões com respeito ao tema, a consolidação da disciplina ainda está se realizando. Observamos a deficiência no montante de professores formados na área necessários a ocupar as vagas nas escolas, os problemas materiais que concorrem para o agravamento na realização do trabalho docente, questões referentes à formação desses profissionais e ao interesse da juventude para o 
trabalho reflexivo próprio da Filosofia, dentre outros problemas que recheiam os dados constantes nos últimos censos e índices e que confirmam muitas das queixas que percebemos nas manifestações dos entrevistados. Contudo, encontramos informações de alguma forma muito estimulantes. É evidente, também, que muitos dos problemas perfilados fogem das iniciativas imediatas possíveis de serem desencadeadas pelos profissionais da educação, mas muitas delas podem efetivamente ser aprimoradas e continuar sendo enfrentadas com empenho e dedicação.

Diante do quadro geral mostrado até aqui, no qual articulamos algumas análises, estimulados que fomos, grandemente, pela riqueza dos dados obtidos a partir das contribuições dos participantes, advogamos que, junto ao que foi apontado ao longo das discussões em torno da "bagagem indispensável ao professor de Filosofia", ainda possa ser considerada a importância implacável da Filosofia da Educação como pano de fundo no qual esteja circunscrito o “ensino de Filosofia”. Entendemos que só assim, ao tratamento da disciplina de Filosofia nas escolas, haverá a incorporação de preocupações mais amplas do que aquela que focaliza apenas a garantia de saberes, competências e/ou habilidades específicos, não obstante reconheçamos a importância desse egrégio objetivo voltado aos conteúdos. Mas, acreditamos que, para isso poder acontecer, o docente da disciplina de Filosofia do ensino médio deverá ter em sua bagagem, além do que já fora apontado anteriormente em várias passagens desse estudo, também os conteúdos próprios à Filosofia da Educação, invariavelmente. Ademais, é a Filosofia da Educação o campo de conhecimentos que, se bem observado, permite em grande parte a constituição de uma identidade fecunda ao professor de Filosofia, pois, em seu âmbito, o encontro do ser filósofo e do ser educador é, de fato, entendido como condição necessária para que parceiros de um mesmo Banquete experimentem os dissabores e degustem os melhores sabores que a vida oferece no decurso da formação humana, considerando todos os elementos filosófico-educacionais que concorrem para tal compreensão. 


\section{Referências}

GALLO, S. Entrevista com o professor Silvio Gallo: Ensino de Filosofia: os principais desafios. 2011.

Disponível:<http: / / filescola.blogspot.com.br/2011/10/entrevista-com-oprofessor-silvio-gallo.html>. Acesso: 15 out. 2012.

MARSHALL, J. P. O professor e sua filosofia. São Paulo: Summus Editorial, 1977.

PARANÁ. Secretaria de Estado da Educação. Resultado do censo escolar 2011. Curitiba: Coordenação de Informações Educacionais, 2011.

NESEF - NÚCLEO DE ESTUDOS E PESQUISAS SOBRE O ENSINO DE FILOSOFIA. Posicionamento dos educadores e pesquisadores do coletivo do NESEF/UFPR sobre as declarações da SEED em relação ao resultado do IDEB do Paraná 2012. Disponível:<http://www.nesef.ufpr.br/paginas.php?noticia=manifestodo-coletivo-do-nesef-sobre-o-resultado-ideb-parana . Acesso: 
Educ. Anál., Londrina, v.1, n.1, p. 133-162, jan./jul. 2016 